\title{
Dependence of bare soil albedo on soil moisture on the moraine of the Zongo glacier (Bolivia): implications for land surface modeling
}

S. Gascoin, ${ }^{1}$ A. Ducharne, ${ }^{1}$ P. Ribstein, ${ }^{1}$ Y. Lejeune, ${ }^{2}$ and P. Wagnon ${ }^{3}$

S. Gascoin, UMR 7619 Sisyphe, Université Pierre et Marie Curie, 4 place Jussieu, 75005 Paris, France. Currently at: Centro de Estudios Avanzados en Zonas Aridas (CEAZA), Campus A. Bello, Universidad de La Serena, La Serena, Chile. (simon.gascoin@ceaza.cl)

A. Ducharne, UMR 7619 Sisyphe, Université Pierre et Marie Curie, 4 place Jussieu, 75005 Paris, France.

P. Ribstein, UMR 7619 Sisyphe, Université Pierre et Marie Curie, 4 place Jussieu, 75005 Paris, France.

Y. Lejeune, Centre d'Etude de la Neige, Météo-France/CNRM, 1441 rue de la Piscine, Domaine Universitaire, 38406 Saint-Martin-d'Hères, France.

P. Wagnon, IRD Great Ice, LGGE, 54 Rue Molière, Domaine Universitaire, BP 96, 38402 Saint-Martin-d'Hères, France.

${ }^{1}$ UMR 7619 Sisyphe, UPMC/CNRS,

Paris, France.

${ }^{2}$ Centre d'Etude de la Neige, Météo-France/CNRM, Grenoble, France. 


\section{Abstract.}

Although the dependence of bare soil albedo on soil moisture is a familiar observation, it is not commonly represented in climate modeling. We investigate the impact of this dependence in a land surface model (LSM) using meteorological data collected on the moraine of a Bolivian glacier. The relationship which is implemented to simulate albedo variations with soil moisture is deduced from a previous field study.

The model is set up at the scale of the meteorological station plot to have the most accurate control on the model calibration and validation. A snow parameter is modified to account for the fact that the model was designed for larger cell sizes. Water content measurements are used to calibrate the parameter controlling the vertical water fluxes within the soil surface layer. This allows us to enhance the model's ability to capture the fast changes in surface soil moisture.

The comparison of simulated ground heat flux and outgoing longwave radiations with observations shows that the model performs well despite the fact that all other parameters are set a priori based on local properties of the surface.

\footnotetext{
${ }^{3}$ Great Ice, IRD/LGGE, Grenoble,
} France. 
The results show that the dependence of bare soil albedo on soil moisture, which causes an increase in the net radiation, importantly influences the turbulent fluxes at the annual and monthly timescales. The mean annual evaporation is increased by $12 \%$. As a consequence, this parameterization modifies the computed runoff, which is reduced by more than $5 \%$ during the rainy season. 


\section{Introduction}

The darkening of soil when it gets wet is a common observation that was already adressed by Angström [1925] and has been theoretically explained for long [e.g. Twomey et al., 1986; Ishida et al., 1991]. It is due to the fact that water replacing air in the uppermost layer of soil tends to increase the likelihood of light absorption by the surface.

Idso et al. [1975] showed in a pioneering field study that bare soil albedo is a linear function of the water content in the top soil layers $(0.2-\mathrm{cm}$ to $10-\mathrm{cm})$. Such a linear relationship has been implemented in several land surface models (LSMs) [Pitman et al., 1991; Acs and Hantel, 1998; Nai et al., 2001; Lawrence and Slingo, 2004; Matsui et al., 2007].

But Idso's work has been challenged by more recent studies which indicated that, for many soil types, a non-linear exponential relationship is more appropriate to depict the dependence of bare soil albedo on water content [Duke and Guérif, 1998; Liu et al., 2002; Lobell and Asner, 2002; Wang et al., 2005; Gascoin et al., 2009a].

However, the bare soil albedo is still set constant in many LSMs applications. For example, a soil albedo parameterization is included in the state-of-the-art LSM ORCHIDEE [Krinner et al., 2005], but is actually not activated (M. Mancip, personal communication). According to Zeng [2005], the soil moisture effect on albedo is not taken into account in the weather forecast models of the National Centers for Environmental Prediction (NCEP) and of the European Centre for Medium-Range Weather Forecasts (ECMWF), whereas the estimated area of bare soil on Earth is $35 \times 10^{6} \mathrm{~km}^{2}$, i.e. $26 \%$ of the total land surface area [excluding Antarctica, see Sterling and Ducharne, 2008]. 
To the authors' knowledge, the only LSM application in which this exponential function was included is reported by Liang et al. [2005]. This modification (combined with modifications of snow and vegetation albedo) markedly improved the existing albedo scheme of the Common Land Model LSM [Dickinson et al., 1993; Nai et al., 2001], but the authors did not assess the effect on the energy and water fluxes.

On the other hand, a good estimate of the albedo over various surfaces is widely recognized as a critical issue in climate modeling. To cite only one recent example, Charlson et al. [2005] pointed out how important is the accuracy of the albedo representation at all scales in order to understand the part of the radiative forcing due to the emission of greenhouse gases in the recent climate change.

We think that this paradox is partly due to the fact that only few studies have addressed the implications of the bare soil albedo dependence on soil moisture in terms of energy and water balance.

McCumber and Pielke [1981] performed sensitivity tests (24-h simulations) in which soil albedo was free to vary as a function of surface moisture according to Idso's formulation. Depending on the soil type, the authors reported a shift of the simulated surface temperature ranging between $-1^{\circ} \mathrm{C}$ and $+2.5^{\circ} \mathrm{C}$. Despite this change, they discarded the effect of the albedo variability because they found that the effect of the soil moisture initialization in the simulation is much stronger. This result was confirmed by the numerical experiments of Clark and Arritt [1995], who found that the albedo effect is lower than the effect of soil moisture availibility for the simulation of an atmospheric convective event.

However, these studies focus on the sensitivity of energy fluxes at short timescales (hourly to daily). In this paper, we report a case study to investigate the following 
question: in a land surface model, what is the effect at the annual timescale of coupling bare soil albedo with soil moisture? To what extent does this dependence modify the computed surface fluxes and the resulting water and energy budgets?

We address this issue using a land surface model forced with meteorological data collected on the moraine of a Bolivian glacier. This site is well suited to this study, because there is no vegetation and the sensitivity of albedo to soil moisture was described in Gascoin et al. [2009a] based on in-situ measurements. The paper is organized as follows: first, the site, the model and the data are described (Sect. 2 and Sect. 3). The modeling strategy is described in Sect. 4 and the results are reported in Sect. 5 .

\section{Site description}

The study site $\left(16^{\circ} 15^{\prime} \mathrm{S}, 68^{\circ} 10^{\prime} \mathrm{W}, 5050 \mathrm{~m}\right.$ a.s.l. $)$ is located on the moraine of the Zongo glacier, near La Paz, Bolivia (Fig. 1). The Zongo glacier (area $2.0 \mathrm{~km}^{2}$ ) is part of the Huayna Potosi massif in the Cordillera Real. A stream gaging station at $4830 \mathrm{~m}$ a.s.l defines the Zongo catchment $\left[3.3 \mathrm{~km}^{2}\right.$, see Soruco et al., 2009].

In this subtropical region, the climate is typically characterized by the alternation of a rainy season and a dry season. The rainy season roughly starts in December and ends in March. The annual precipitation varies between $600 \mathrm{~mm}$ and $1200 \mathrm{~mm}$ [for more details about local climate, see Ribstein et al., 1995; Wagnon et al., 2001].

In the central Andes, the vegetation is sparse above $3500 \mathrm{~m}$ a.s.l [Kuentz et al., 2007]. On the moraine of the Zongo glacier, the altitude exceeds $4800 \mathrm{~m}$ a.s.l, and the vegetation cover is not significant. The non-glacierized areas are mainly covered by glacial deposits coming from the weathering of the silicate bedrock. These deposits appear clearly on the 
aerial photograph (Fig. 1) with colours ranging from light to dark gray. Darkest areas correspond to outcrops of granodiorite with steep slopes (except for a small lake).

Meteorological data have been collected since 2004 in the ORE-GLACIOCLIM automatic weather station (hereinafter referred to as ORE-AWS). The data are described in details in Sect. 3.2. The station is situated on a rounded part of the lateral moraine, forming a convex relief where runoff is likely to be enhanced by the strong topographic gradients (see Sect. 3.3). But the plot of the ORE-AWS is installed on is basically flat (dimensions $10 \times 10 \mathrm{~m}^{2}$ ). In the ORE-AWS, there is no vegetation at all. The whole plot is homogeneously covered by a light gray soil. Granulometric analysis revealed that the surface layer (top 5-cm) belongs to the sand class in the USDA texture triangle [see Gascoin et al., 2009a].

\section{Model and data}

\subsection{Model description}

The Catchment Land Surface Model [CLSM, Koster et al., 2000a; Ducharne et al., $2000]$ is used to compute water and energy fluxes at the land surface. This model has been evaluated in a number of model intercomparison projects at various scales [e.g. Nijssen et al., 2003; Boone et al., 2004; Koster et al., 2006].

CLSM is a land surface model that includes parameterizations from the Mosaic LSM [Koster and Suarez, 1996] to solve the water and energy budgets at the land surface. It also incorporates the three-layer snow model of Lynch-Stieglitz [1994].

CLSM uses TOPMODEL equations [Beven and Kirkby, 1979] to account for the influence of topography on soil moisture patterns and to generate runoff. The land surface is partioned into hydrological catchment (typically 1000-10000 km²). Each unit catch- 
ment includes a conceptual water table. At each timestep (20-min), the mean water table depth is calculated from the catchment's average soil moisture. The subgrid variability of the water table depth is derived from the topographic index distribution. The resulting distribution of the water table depth allows the partitioning of the catchment space into three regions with distinct hydrological regimes (saturated, intermediate and stressed). For each region, runoff and evaporation are computed independently using specific parameterizations (mostly taken from the Mosaic LSM).

In the vertical direction, the water fluxes are computed based on Richards equation and can be downward or upward. The soil moisture is represented by three non-traditional prognostic variables, which can be related to the water content within three layers, that is, the surface layer, the root zone layer and the deep soil layer [see Koster et al., 2000a]. In this paper, we focus on the surface layer. Its depth has been fixed to 5 -cm to be consistent with the measurements depth. The bulk surface layer wetness $\omega$, i.e. the degree of saturation, is computed with:

$$
\omega=\sum_{i=1}^{3} \omega_{i} A_{i}
$$

where $i$ designates one of the three regions in the catchment and $\omega_{i}$ and $A_{i}$ are the surface layer wetness and fractional area of the region $i$.

In the analysis below, we express the soil moisture in volumetric water content (VWC in $\mathrm{m}^{3} / \mathrm{m}^{3}$, volume of water per volume of soil). The VWC in the surface layer $\theta$ is given by:

$$
\theta=\omega \phi
$$

where $\phi$ is the soil porosity. 


\subsection{Meteorological data}

All the meteorological data are taken from the ORE-AWS records (1-hr mean values). These data are available at http://www-lgge.ujf-grenoble.fr/ServiceObs/.

Meteorological forcing include wind speed, air temperature, relative humidity, incoming longwave and shortwave radiations and rainfall. The precipitation phase is determined using an air temperature threshold of $0.5^{\circ} \mathrm{C}$, following L'hôte et al. [2005] who showed that $90 \%$ of the precipitation in this area is solid below this temperature.

Calibration and validation data include upward longwave radiations, ground heat flux, albedo and soil water content. Albedo is computed every 10 seconds as the ratio of reflected to incoming shortwave radiations, but only the mean value is recorded every 30 min. Volumetric water content is logged every hour in the top 5 -cm using a ThetaProbe Soil Moisture Sensor since November 2007 [Delta-T Devices, 1999].

The meteorological dataset is not continuous because the severe environmental conditions hinder the maintenance of the station (Fig. 3). The gaps are filled using data collected in the nearby meteorological station ORE2, which was set up on the glacier, at the same altitude as the ORE-AWS (Fig. 1), during the same period. Good correlations exist between each variable of the two datasets, allowing us to evaluate the missing values. This was done for all the atmospheric forcing except for the precipitation rate, as the ORE2 station does not include a precipitation gage. To solve this issue, we used daily data from a rain gage located at the Plataforma Zongo, $1000 \mathrm{~m}$ away from the glacier tongue, at an altitude of $4770 \mathrm{~m}$. The daily water depths were interpolated to the hourly timestep based on the observation of the marked diurnal cycle [Sicart et al., 2002]. 
The period of reconstructed data represent $20 \%$ of the calibration period and $28 \%$ of the validation period. In the next sections, reconstructed data are not considered when averaging the variables or calculating coefficients to measure the performance of the simulations.

\subsection{Model set-up}

The focus of this study is on surface fluxes. Therefore, we chose to set up the model at the scale of the ORE-AWS, which is a $10 \times 10 \mathrm{~m}^{2}$ plot. This allows us to have the most accurate control on the model calibration and validation. A catchment-based approach would require the spatialization of the meteorological data. Considering the extreme variability of the topography in the study area (see the elevation contour lines over the potential catchment in figure 1), the data upscaling would largely increase the uncertainty on the computed fluxes.

The input data include meteorological forcing, soil parameters and the topographic index distribution. The land surface type is bare soil for the whole plot, thus the vegetation parameters do not need to be considered. Following in-situ data, The soil parameters are deduced from Cosby et al. [1984] for the sand class (Table 1), except for porosity, which is set as the maximum value of the water content time series i.e. $\phi=0.45$ (Sect. 3.2).

This modeling approach, however, raises a conceptual problem. As the ORE-AWS plot is not a catchment, it is not possible to define its topographic index distribution (TID). Because of the morphology of the study area (Sect. 2), we chose to use the TID parameters calculated for a mountaineous catchment, namely the Sleepers River catchment [Vermont, USA Stieglitz et al., 1997]. This distribution is referred to as TID1 below. To evaluate the influence of this choice, we have tested two other different TID prior to further calibration: 
TID2 refers to the TID of the Somme River catchment (France), which is a rather flat catchment [see Gascoin et al., 2009b] and TID3 refers to the TID of non-glacierized area extracted from the Zongo catchment (delineated in Fig. 1). The first three moments for each TID are given in Table 2. The results are presented in Sect. 5.1.

\subsection{Bare soil albedo parameterization}

In the absence of snow, the surface energy balance equation in CLSM is:

$$
S W_{n}+L W_{\text {in }}=\frac{C_{H} \delta T_{C}}{\Delta t}+L W_{\text {out }}+H+\lambda E+G
$$

$S W_{n}$ : net shortwave radiation absorbed at the surface $\left(\mathrm{W} \cdot \mathrm{m}^{-2}\right)$

$L W_{\text {in }}$ : incoming longwave radiation at the surface $\left(\mathrm{W} . \mathrm{m}^{-2}\right)$

$C_{H}$ : heat capacity of the surface $\left(\mathrm{J} \cdot \mathrm{K}^{-1} \cdot \mathrm{m}^{-2}\right)$

$\delta T_{C}$ : change of surface temperature over a timestep $(\mathrm{K})$

$\Delta t:$ timestep duration (s)

$L W_{\text {out }}$ : upward longwave radiation at the surface $\left(\mathrm{W} . \mathrm{m}^{-2}\right)$

$H$ : sensible heat flux $\left(\mathrm{W} . \mathrm{m}^{-2}\right)$

$\lambda$ : latent heat of vaporization $\left({\left.\mathrm{J} . \mathrm{kg}^{-2}\right)}^{-2}\right.$

$E$ : evaporation rate $\left(\mathrm{kg} \cdot \mathrm{s}^{-1} \cdot \mathrm{m}^{-2}\right)$

$G$ : ground heat flux $\left(\mathrm{W} . \mathrm{m}^{-2}\right)$

The net shortwave radiation is deduced from the incoming shortwave radiation $S W_{i n}$, using the surface albedo $\alpha$ :

$$
S W_{n}=(1-\alpha) S W_{i n}
$$


Therefore, a decrease in albedo acts like a positive radiative forcing. In the absence of vegetation, the surface albedo in CLSM is equal to the bare soil albedo $\alpha_{b}$ and does not vary with time. Based on detailed in-situ measurements [Gascoin et al., 2009a], we implemented an exponential relationship between bare soil albedo and water content:

$$
\alpha_{b}=A \exp (-B \theta)+C
$$

where $\alpha_{b}$ is the soil albedo, $\theta$ the volumetric water content in the top 5 -cm and $A, B$ and $C$ are parameters. $B$ defines the curvature of the exponential relationship, whereas $A$ and $C$ define the extremes values. In the absence of VWC data for the whole simulation period, $B$ is taken from the fit performed with $2007-2008$ data i.e. $B=12.7$ [waveband $305 \mathrm{~nm}$ to $2800 \mathrm{~nm}$, see Gascoin et al., 2009a]. This value is consistent with the values found by Liang et al. [2005] from satellite measurements over North America, i.e. $B=14.4$ for visible band (300 nm-700 nm) and $B=11.6$ for near-infrared band (700 nm-5000 nm). This comparison suggest that the $B$ parameter is independant of the measurement scale.

Regarding the parameters $A$ and $C$, as the extreme albedo values have slightly changed between 2004 to 2008, the values for $A$ and $C$ were not taken from the 2007-2008 fit, but were deduced from the following hypotheses:

- the upper bound of the soil albedo is reached when the soil water content is at residual point. In the CLSM, the residual point corresponds to a soil wetness of $18 \%(\theta=0.081)$

- the lower bound is reached when soil wetness is $100 \%(\theta=0.45)$.

These extreme values of VWC are verified to occur during the 2007-2008 monitoring period, but cannot be better constrained. On the other hand, the albedo extreme values are determined using the 2004-2006 albedo time series (Fig. 2), leading to $A=0.42$ and $C=0.16$. The main difference with the fitting parameters for 2007-2008 $(A=0.31$, 
$C=0.15)$ is the value of $A$, indicating a decrease in the dry soil albedo with time, which appears in Fig. 2 on the minimum albedo values and is probably due to instrumental drift.

As CLSM runs using a 20-min timestep, bare soil albedo is computed every 20-min. If this new parameterization is not activated, the bare soil albedo is set to 0.3 , which is the most frequent value in the ORE-AWS dataset.

\subsection{Snow parameterization}

The objective of this work is not to investigate snow albedo. A detailed study of snow processes and modeling in the same area is reported by Lejeune et al. [2007]. However, the occurence of snow cover has to be properly simulated to allow the analysis of the snow-free periods. For that purpose, we modified the minimum average snow amount $S_{\min }(\mathrm{mm}$ in water equivalent) above which the snow can accumulate. If the average snow amount over the grid cell is less than $S_{\min }$, then snow cover is forced to melt during the time step. As $S_{\text {min }}$ is computed as the average amount over the grid cell surface, it depends strongly on the scale of modeling. The default value in CLSM is $S_{\min }=1-6 \mathrm{~mm}$. This value is adapted to kilometric cell size, where snow cover is non-uniform. On the contrary, over the $10 \times 10 \mathrm{~m}^{2}$ ORE plot, an average snow amount of $1 \mathrm{e}-6 \mathrm{~mm}$ is unlikely to persist longer than 20-min. Therefore $S_{\min }$ has been fixed to $1 \mathrm{~mm}$.

The fresh snow density was also changed to $300 \mathrm{~kg} / \mathrm{m}^{3}$, which is the value reported by Sicart et al. [2002] for the same study site.

\section{Modeling strategy}


The simulation exercise is split into two period (Fig. 3). The sensitivity to the topographic index distribution is tested over the calibration period. Next, the model's soil parameters are calibrated against VWC data, which are only available from 07 November 2007 to 21 June 2008. The simulation with the default parameter set is noted CAL0 and the calibrated simulation is noted CAL1. Then, the model is run using the same parameter set as CAL1 over a longer period (01 September 2004 to 01 April 2006), to perform validation and sensitivity tests (simulations VAL1, VAL1a, VAL1b). Thus, simulation VAL1 is equivalent to CAL1, but the simulation period is longer. Simulation VAL1a refers to the simulation in which the exponential variation of bare soil albedo with water content is activated (Sect. 3.4). VAL1b refers to a simulation in which the bare soil albedo is directly forced by the observed albedo time series, for timesteps when the observed value is less than 0.32 . When $\alpha>0.32$, the observed soil albedo is affected by snow cover or low solar zenith angle. In this case, the input values are interpolated from the observed values, using nearest-neighbor method.

For all simulations, the initial conditions are achieved by a ten-time spin-up, i.e. by running the model over ten repetitions of the meteorological forcing corresponding to the simulation period.

\section{Results}

\subsection{Sensitivity to the topographic index distribution}

Before testing the dependence of albedo on soil moisture, it is critical to simulate realistic soil moisture variations in the top 5-cm. However, the simulation of the soil moisture at the very surface is particularly challenging for several reasons. First, it relies heavily on the precipitation measurement. In this area, the uncertainty on precipitation depth is large 
due to the frequent occurrence of snow. Secondly, large variations can occur during short periods. Thirdly, water content within the surface layer not only depends on atmospheric forcing, but also on the moisture conditions of underlying soil layers.

We performed three preliminary tests to assess the sensitivity of CLSM's surface layer to the topographic index distribution (Sect. 3.3). We focused on the surface layer VWC, in comparison with VWC measurements. The results are depicted in Fig. 4. The main effect is a vertical translation of the simulated VWC, due to the fact that the TID controls the TOPMODEL water table depth.

Fig. 4 also shows that the most important aspect is the mean value of the TID, whereas the amplitude of variations is not strongly affected by the TID. This result is consistent with the wide body of literature about TOPMODEL's sensitivity to the TID, including the conclusion of Franchini et al. [1996], who demonstrated that, apart from the sensitivity to the mean topographic index, “TOPMODEL shows such limited sensitivity to the basin's actual index curve that it is possible (...) to replace it with other curves taken within a relatively broad band, without significantly altering the sequence of discharges generated". In contrast, the latter is significantly influenced by the mean topographic index, which depends as much on local topography as on the DEM resolution, so that it is mandatory to calibrate the transmissivity parameters of TOPMODEL [e.g. Wolock and McCabe, 1995; Saulnier et al., 1997; Ducharne, 2009].

We set TID1 as the default distribution for the model calibration, validation and sensitivity tests reported below.

\subsection{Calibration of the surface layer parameter}


As mentioned above, the VWC data collected in the ORE-AWS during the rainy season is an essential information to improve the simulation of the soil moisture in the surface layer. These data allowed us to calibrate the surface layer parameterization. In this study, only manual calibration was performed without using an optimization technique.

We chose to calibrate only one parameter, $a_{\tau 2}$ [Equation (17) in Ducharne et al., 2000], which defines the timescale of moisture transfer between the surface layer and the root zone layer. The standard values of $a_{\tau 2}$ in CLSM are tabulated for each soil class. For the sand class, the default value is $a_{\tau 2}=2.45 \mathrm{e}-08 \mathrm{s.m}{ }^{3}$. Figure 5 shows the simulated water content in the surface layer before (simulation CAL0) and after calibration (simulation CAL1), in comparison with the VWC data. If $a_{\tau 2}$ is set to the default value (CAL0), the hydraulic connectivity between the root zone and the surface layer is too strong. This induces a constant replenishment of the surface layer during periods of strong evaporative demand, e.g. at the end of the rainy season, whereas the measurements indicate abrupt decreases in the VWC. On the other hand, this default parameter prevents water from accumulating in the surface layer after precipitation events, as it can be observed several times in the VWC record.

A higher value of $a_{\tau 2}$ tends to limit the vertical water fluxes between the surface layer and the root zone. As a result, the surface layer is more sensitive to the atmospheric forcing and the buffering effect by the deeper soil is reduced. This led us to increase the magnitude of $a_{\tau 2}\left(a_{\tau 2}=2.16 \mathrm{e}-06 \mathrm{~s} . \mathrm{m}^{3}\right.$ in CAL1), which improves markedly the simulated VWC by increasing the variation amplitude. The fast response of the observed signal is better captured. For example, the model reproduces properly the drastic change of water content in March 2008. The change in $a_{\tau 2}$ contributes to lower the root mean squared 
error (RMSE) and to strengthen the correlation between the simulated and observed signal (Nash-Sutcliffe efficiency raised from 0.59 to 0.73 ).

\subsection{Validation}

\subsubsection{Albedo}

The graphical analysis of the simulated albedo is presented in Fig. 6. The simulated surface albedo (i.e. including the snow cover contribution) is represented against the observed albedo.

Lejeune et al. [2007] reported that the snow pack is particularly ephemeral in the area (and thus difficult to simulate with a classical snow model), mainly because of extreme solar radiation conditions. Figure 6 shows that some albedo values are overestimated, which may indicate that (i) the model underestimates snow melting rates; or (ii) the determination of the precipitation phase is not accurate. Nevertheless, there is a clear separation of two subsets $(\alpha>0.32$ and $\alpha<0.32$, cf. Sect. 4$)$ in all simulations, which demonstrates that the snow parameterization (Sect. 3.5) is adapted to represent the occurence of snow cover on the moraine of the Zongo glacier, allowing a good match between the simulated and observed snow-free periods.

The albedo values ranging between 1 and 0.32 correspond to days with significant snow cover. They are not primarily affected by the soil albedo parameterization, therefore we focus on the values lower than 0.32 . Fig. 6 shows that VAL1 with a constant albedo does not properly represent the observed values. In simulation VAL1a, the albedo parameterization induces an extension of the range of simulated albedo, and thus a better fit of the data, although the bare soil albedo is a bit underestimated. This results in fewer positive residuals compared to VAL1. 
However, the points in VAL1 do not closely match the 1:1 line. This may be caused by discrepancies in the simulated surface moisture, in spite of the calibration effort (Sect. 5.2), or by the imperfection of the albedo parameterization (Eq. 5), which was established using the 2007-2008 dataset, as no VWC data are available for the validation period (cf. Sect. 3.4).

The statistical analyses of these results confirm the fact that the albedo is better estimated in VAL1a and VAL1b. As shown in Table 3, simulations VAL1a and VAL1b have lower bias and RMSE, and higher coefficient of determination $\left(r^{2}\right)$ than VAL1. These indicators were also computed on the sub-sample of daily albedo lower than 0.32 , which emphasizes the improvement of the snow-free albedo representation. These results hold at lower timesteps.

\subsubsection{Energy fluxes}

Figure 7 shows the comparison of VAL1, VAL1a and VAL1b against observations, for ground heat flux $\left(\mathrm{W} / \mathrm{m}^{2}\right)$ and upward longwave radiations $\left(\mathrm{W} / \mathrm{m}^{2}\right)$. The three simulations yield satisfactory estimates of the fluxes at the daily time step. Note that, except for $a_{\tau 2}$ (cf. Sect. 5.2) and $S_{\min }$ (cf. Sect. 3.5), all other parameters were set a priori based on local properties of the surface.

The variability of the bare soil albedo does not clearly improve the validation of the simulated fluxes. Although VAL1a and VAL1b tend to increase the correlation between the simulated and observed fluxes (increase in the coefficient of determination), the RMSE and bias of the upward longwave radiation are slightly increased (Figure 7). Overall, the bare soil albedo parameterization does not clearly modify the realism of these fluxes. The 
section below shows that other terms of the energy balance are more importantly affected by the bare soil albedo variability.

\subsection{Impact on surface water and energy budgets}

The results are summarized in Fig. 8 and Table 4, which sums up the effect of the bare soil albedo parameterization on key variables of the water and energy budgets. The soil moisture effect on albedo causes a considerable increase in the mean net radiation $(+7 \%$ to $+13 \%$, see also Fig. 8). This is due to the increased absorbed shortwave radiation when the surface is wet (Eq. 4 and 5). Results show that the additional absorbed energy is mostly dissipated into sensible and latent heat fluxes. As a result, the net evaporation increases by $12 \%$ between VAL1a and VAL1, and the mean surface temperature is higher. The variation of the Bowen ratio is relatively low because the sensible heat flux and the evaporation are both increased. In general, the impact on the output variables is less important for VAL1b than VAL1a, certainly because the low albedo values are underestimated in simulation VAL1a (see Sect. 5.3.1).

Interestingly, coupling the bare soil albedo with surface moisture exerts a low negative feedback on the calculated soil moisture. Lower albedo means stronger evaporation rate, which causes a slight decrease in the surface water content. Lower VWC tends in turn to limit the decrease in albedo.

Figure 8 shows that the simulated turbulent fluxes in VAL1a and VAL1b are systematically greater at the monthly time step than those calculated with a constant albedo. For all displayed variables (which are the terms of the energy balance equation), the monthly mean values are almost identical during the dry season (from June to October). The difference is marked between November and May, when the soil albedo is frequently 
impacted by the precipitations of the rainy season. Notably, the difference between the evaporation rates averages $15 \mathrm{~mm} /$ month in January 2004 (+32\%). As a consequence, the simulated runoff (sum of surface runoff and base flow) is also impacted (Fig. 9). The annual mean decreases by $3-4 \%$, but the total runoff is reduced by more than $5 \%$ during the two rainy seasons of the simulation period. The relative difference between VAL1 and VAL1a reaches $-9.4 \%$ in January 2004 .

The sensitivity of runoff is rather low at the annual scale because, in this area, the evaporation rate is much lower than the calculated runoff. In these conditions, a large variation of evaporation does not importantly affect the annual mean runoff. Thus, a stronger impact may be observed in areas where the ratio evaporation/runoff is higher, e.g. in flat areas of semi-arid zones.

\section{Conclusions}

Using a land surface model and 25 months of hourly meteorological data, we investigated the effect of coupling bare soil albedo with surface soil moisture on the moraine of the Zongo glacier (Bolivia). The relationship between albedo and soil water content was deduced from previous field measurements.

We adapted one parameter to account for the downscaling of the snow representation. Then, only one parameter was calibrated, using water content measurements, in order to accurately represent the surface moisture variations. The model was successfully validated using observed ground heat flux and outgoing longwave radiations.

Our study clearly demonstrates that implementing the effect of soil moisture on bare soil albedo importantly influences the surface fluxes at the monthly and annual scale, even if we could not provide evidence of their improvement by lack of sufficient data. 
For example, the mean annual evaporation rate was increased by $+12 \%$. At the monthly timescale, the impact on the turbulent fluxes is stronger during the rainy season. The consequence is a reduction by more than $5 \%$ in the simulated runoff during this period.

This study raises a scale issue. To avoid the uncertainties due to data extrapolation, the model was set up at the local scale $\left(100 \mathrm{~m}^{2}\right)$, whereas the typical scale for land surface modeling is $10000 \mathrm{~km}^{2}$. However, we presume that the conclusions would be similar at a larger scale, on the condition that the domain is only covered by bare soil. To demonstrate it, it becomes critical to use an LSM which simulates the lateral distribution of soil moisture. Therefore, the CLSM is a potential tool, because it takes into account the influence of the topography on the soil moisture patterns.

This bare soil parameterization is a step toward an enhanced coupling of water and energy fluxes in LSMs. It opens interesting perspectives in terms of land-atmosphere feedbacks, as the interplay between surface energy and water balances is often considered as a key process in climate modeling [Eltahir, 1998; Koster et al., 2000b]. We think that the effect of the bare soil albedo variability needs to be further investigated in other regions, especially in areas where the soil moisture exerts a strong influence on precipitation variability [e.g. the Sahel region Koster et al., 2004]. Such studies cannot be achieved without accurate monitoring of the soil moisture and albedo, in order to better assess their dependence over various bare surfaces.

Acknowledgments. Work on Zongo catchment was funded by Naturalia \& Biologia and the French Observatoire de la Recherche en Environnement (ORE) GLACIOCLIM (IRD, French Research Ministry) with the support of Instituto de Hidraulica e Hidrologia, La Paz, Bolivia. 


\section{References}

Acs, F., and M. Hantel (1998), The land-surface flux model PROGSURF, Global Planet. Change, 19, 19-34, doi:10.1016/ S0921-8181(98)00039-3.

Ångström, A. (1925), The albedo of various surfaces of ground, Geograf. Ann., 7, 323-342.

Beven, K. J., and M. J. Kirkby (1979), A physically based, variable contributing area model of basin Hydrol., Hydrolog. Sci. J., 24(1), 43-69.

Boone, A., et al. (2004), The Rhône-Aggregation Land Surface Scheme Intercomparison Project: An Overview., J. Climate, 17, 187-208, doi:10.1175/1520-0442(2004)017.

Caballero, Y., P. Chevallier, R. Gallaire, and R. Pillco (2004), Flow modeling in a high mountain valley equipped with hydropower plants: Rio Zongo Valley, Cordillera Real, Bolivia, Hydrol. Process., 18, 939-957, doi:10.1002/hyp.1339.

Charlson, R. J., F. P. J. Valero, and S. J. H. (2005), Atmospheric science: in search of balance, Science, 308(5723), 806-807, doi:10.1126/science.1108162.

Clapp, R. B., and G. M. Hornberger (1978), Empirical equations for some soil hydraulic properties, Water Resour. Res., 14(4), 601-604.

Clark, C. A., and P. W. Arritt (1995), Numerical Simulations of the Effect of Soil Moisture and Vegetation Cover on the Development of Deep Convection., J. Appl. Meteorol., 34, 2029-2045, doi:10.1175/1520-0450(1995)034¡2029:NSOTEO¿2.0.CO;2.

Cosby, B. J., G. M. Hornberger, R. B. Clapp, and T. R. Ginn (1984), A statistical exploration of the relationships of soil moisture characteristics to the physical properties of soils, Water Resour. Res., 20(6), 682-690.

Delta-T Devices (1999), ThetaProbe Soil Moisture Sensor type ML2x User Manual, DeltaT Devices, Cambridge, UK, v1.21 ed. 
Dickinson, R. E., A. Henderson-Sellers, and P. J. Kennedy (1993), Biosphere-atmosphere transfer scheme (BATS) version 1e as coupled to the NCAR Community Climate Model, Tech. rep., NCAR, Boulder, Colorado.

Ducharne, A. (2009), Explicitation of an important scale dependence in topmodel, Hydrol. Earth Syst. Sci., submitted.

Ducharne, A., R. D. Koster, M. Suarez, M. Stieglitz, and P. Kumar (2000), A catchmentbased approach to modeling land surface processes in a GCM - Part 2 : Parameter estimation and model demonstration, J. Geophys. Res., 105 (D20), 24,823-24,838.

Duke, C., and M. Guérif (1998), Crop reflectance estimate errors from the sail model due to spatial and temporal variability of canopy and soil characteristics, Remote Sens. Environ., 66(3), 286-297, doi:10.1016/S0034-4257(98)00062-5.

Eltahir, E. A. B. (1998), A soil moisture-rainfall feedback mechanism 1. Theory and observations, Water Resour. Res., 34, 765-776, doi:10.1029/97WR03499.

Franchini, M., J. Wendling, C. Obled, and E. Todini (1996), Physical interpretation and sensitivity analysis of the topmodel, J. Hydrol., 175(1-4), 293-338, doi:10.1016/S00221694(96)80015-1.

Gascoin, S., A. Ducharne, P. Ribstein, E. Perroy, and P. Wagnon (2009a), Sensitivity of bare soil albedo to surface soil moisture on the moraine of the Zongo glacier (Bolivia), Geophys. Res. Lett., 36, L02405, doi:10.1029/2008GL036377.

Gascoin, S., A. Ducharne, P. Ribstein, M. Carli, and F. Habets (2009b), Adaptation of a catchment-based land surface model to the hydrogeological setting of the Somme River basin (France), J. Hydrol., 368(1-4), 105-116, doi:10.1016/j.jhydrol.2009.01.039. 
Idso, S., R. Jackson, R. Reginato, B. Kimball, and F. Nakayama (1975), The dependence of bare soils albedo on soil water content, J. Appl. Meteorol., 14, 109-113, doi: 10.1175/1520-0450(1975)014;0109:TDOBSA¿2.0.CO;2.

Ishida, T., H. Ando, and M. Fukuhara (1991), Estimation of complex refractive index of soil particles and its dependence on soil chemical properties, Remote Sens. Environ., 38, 173-182.

Koster, R., and M. J. Suarez (1996), Energy and water balance calculations in the Mosaic LSM, Tech. Rep. 9, NASA Technical Memorandum 104606.

Koster, R. D., M. J. Suarez, A. Ducharne, M. Stieglitz, and P. Kumar (2000a), A catchment-based approach to modeling land surface processes in a general circulation model 1. Model structure, J. Geophys. Res., 105, 24,809-24,822, doi: 10.1029/2000JD900327.

Koster, R. D., M. J. Suarez, and M. Heiser (2000b), Variance and Predictability of Precipitation at Seasonal-to-Interannual Timescales, J. Hydrometeorol., 1, 26-46, doi: $10.1175 / 1525-7541(2000) 001$.

Koster, R. D., et al. (2004), Regions of Strong Coupling Between Soil Moisture and Precipitation, Science, 305, 1138-1141, doi:10.1126/science.1100217.

Koster, R. D., et al. (2006), GLACE: The Global Land Atmosphere Coupling Experiment. Part I: Overview, J. Hydrometeorol., 7, 590-610, doi:10.1175/JHM510.1.

Krinner, G., N. Viovy, N. de Noblet-Ducoudré, J. Ogée, J. Polcher, P. Friedlingstein, P. Ciais, S. Sitch, and I. C. Prentice (2005), A dynamic global vegetation model for studies of the coupled atmosphere-biosphere system, Global Biogeochem. Cy., 19, doi: 10.1029/2003GB002199. 
Kuentz, A., A. G. de Mera, M. P. Ledru, and J. C. Thouret (2007), Phytogeographical data and modern pollen rain of the puna belt in southern Peru (Nevado Coropuna, Western Cordillera), J. Biogeogr., 34, 1762-1776, doi:10.1111/j.1365-2699.2007.01728.x.

Lawrence, D. M., and J. M. Slingo (2004), An annual cycle of vegetation in a GCM. Part I: implementation and impact on evaporation, Clim. Dyn., 22, 87-105, doi: $10.1007 / \mathrm{s} 00382-003-0366-9$.

Lejeune, Y., P. Wagnon, L. Bouilloud, P. Chevallier, P. Etchevers, E. Martin, J.-E. Sicart, and F. Habets (2007), Melting of Snow Cover in a Tropical Mountain Environment in Bolivia: Processes and Modeling, J. Hydrometeorol., 8, 922-937, doi:10.1175/JHM590.1.

L'hôte, Y., P. Chevallier, A. Coudrain, Y. Lejeune, and P. Etchevers (2005), Relationship between precipitation phase and air temperature: comparison between the bolivian Andes and the swiss Alps, Hydrol. Sci. J., 50(6), 989-997, doi:10.1623/hysj.2005.50.6.989. Liang, X. Z., et al. (2005), Development of land surface albedo parameterization based on moderate resolution imaging spectroradiometer (modis) data, J. Geophys. Res., 110, D11,107, doi:10.1029/2004JD005579.

Liu, W. D., F. Baret, X. F. Gu, Q. X. Tong, L. F. Zheng, and B. Zhang (2002), Relating soil surface moisture to reflectance, Remote Sens. Environ., 81, 238-246, doi:10.1016/S00344257(01)00347-9.

Lobell, D. B., and G. P. Asner (2002), Moisture effects on soil reflectance, Soil Sci. Soc. Am. J., 66, 722-727.

Lynch-Stieglitz, M. (1994), The Development and Validation of a Simple Snow Model for the GISS GCM., J. Climate, \%, 1842-1855, doi:10.1175/15200442(1994)007;1842:TDAVOA¿2.0.CO;2. 
Matsui, T., A. Beltrán-Przekurat, R. A. Pielke, D. Niyogi, and M. B. Coughenour (2007), Continental-scale multiobservation calibration and assessment of Colorado State University Unified Land Model by application of Moderate Resolution Imaging Spectroradiometer (MODIS) surface albedo, J. Geophys. Res., 112, G02028, doi: 10.1029/2006JG000229.

McCumber, M. C., and R. A. Pielke (1981), Simulation of the effects of surface fluxes of heat and moisture in a mesoscale numerical model 1. Soil layer, J. Geophys. Res., 86, 9929-9938.

Nai, Y., X. Zeng, and R. E. Dickinson (2001), Common Land Model (CLM) Technical Documentation and User's Guide.

Nijssen, B., et al. (2003), Simulation of high latitude hydrological processes in the TorneKalix basin: PILPS Phase 2(e) - 2: Comparison of model results with observations, Global Planet. Change, 38, 31-53, doi:10.1016/S0921-8181(03)00004-3.

Pitman, A. J., Z. L. Yang, J. G. Cogley, and A. Henderson-Sellers (1991), Description of the bare essentials of surface transfer for the bureau of Meteorol. Res. centre AGCM, BMRC Res. Report, (32).

Ribstein, P., E. Tiriau, B. Francou, and R. Saravia (1995), Tropical climate and glacier Hydrol.: a case study in Bolivia, J. Hydrol., 165, 221-234, doi:10.1016/00221694(94)02572-S.

Saulnier, G.-M., C. Obled, and K. Beven (1997), Analytical compensation between dtm grid resolution and effective values of staurated hydraulic conductivity within the topmodel framework, Hydrol. Process., 11, 1331-1346. 
Sicart, J. E., P. Ribstein, J. P. Chazarin, and E. Berthier (2002), Solid precipitation on a tropical glacier in Bolivia measured with an ultrasonic depth gauge, Water Resour. Res., 38(10), 1189, doi:10.1029/2002WR001402.

Soruco, A., et al. (2009), Mass balance of Glaciar Zongo, Bolivia, between 1956 and 2006, using glaciological, hydrological and geodetic methods, Ann. Glaciol., 50, 1-8.

Sterling, S., and A. Ducharne (2008), Comprehensive data set of global land cover change for land surface model applications, Global Biogeochem. Cy., 22, GB3017, doi: 10.1029/2007GB002959.

Stieglitz, M., D. Rind, J. Famiglietti, and C. Rosenzweig (1997), An efficient approach to modeling the topographic control of surface Hydrol. for regional and global climate modeling, J. Climate, 10, 118-137.

Twomey, S. A., C. F. Bohren, and J. L. Mergenthaler (1986), Reflectance and albedo differences between wet and dry surfaces, Appl. Optics, 25(3), 431-437.

Wagnon, P., P. Ribstein, B. Francou, and J. E. Sicart (2001), Anomalous heat and mass budget of Glaciar Zongo, Bolivia, during the 1997/98 El Niño year, J. Glaciol., 4\%, $21-28$.

Wang, K. C., P. C. Wang, J. M. Liu, M. Sparrow, S. Haginoya, and X. J. Zhou (2005), Variation of surface albedo and soil thermal parameters with soil moisture content at a semi-desert site on the western tibetan plateau, Bound.-Lay. Meteorol., 116, 117-129, doi:10.1007/s10546-004-7403-z.

Wolock, D. M., and G. J. McCabe (1995), Comparison of single and multiple flow direction algorithms for computing topographic parameters in TOPMODEL, Water Resour. Res., 31, 1315-1324, doi:10.1029/95WR00471. 
Zeng, X. (2005), Overview of soil, vegetation, and snow albedos in weather and climate models. http://ams.confex.com/ams/Annual2005/techprogram/paper_88110.htm 
Table 1. Soil parameters. $K_{S C}$ is given for a compacted soil.

\begin{tabular}{|c|c|c|}
\hline$\overline{\text { Variable }}$ & Units & Value \\
\hline Soil depth $D$ & $\mathrm{~m}$ & 3.00 \\
\hline Root zone depth $D_{R Z}$ & $\mathrm{~m}$ & 0.20 \\
\hline Porosity $\omega$ & - & 0.45 \\
\hline Compacted saturated hydraulic conductivity $K_{S C}$ & $\mathrm{~m} \cdot \mathrm{s}^{-1}$ & $4.7 \mathrm{e}-05$ \\
\hline Decay factor with depth of saturated hydraulic conductivity $\nu$ & $\mathrm{m}^{-1}$ & 3.26 \\
\hline Clapp and Hornberger [1978] b & - & 2.79 \\
\hline Saturated soil matrix potential $\psi_{S}$ & $\mathrm{~m}$ & -0.069 \\
\hline
\end{tabular}

Table 2. Parameters describing the three tested topographic index distributions.

\begin{tabular}{llll}
\hline TID & TID1 & TID2 & TID3 \\
\hline Mean $\bar{x}$ & 7.36 & 9.85 & 7.39 \\
Variance $\sigma_{x}^{2}$ & 5.51 & 5.37 & 4.95 \\
Skewness $\gamma_{x}$ & 1.23 & 1.41 & 0.42 \\
DEM resolution $(\mathrm{m})$ & 30 & 75 & 50 \\
\hline
\end{tabular}

Table 3. Validation of the albedo over the 2004-2006 simulation period. The coefficients are computed from daily mean values.

\begin{tabular}{lllll}
\hline & Simulation & VAL1 & VAL1a & VAL1b \\
& Bare soil albedo & constant & $f($ VWC $)$ & Forced \\
\hline All values & Bias & 0.059 & 0.0023 & 0.025 \\
& RMSE & 0.14 & 0.12 & 0.11 \\
& $\mathrm{r}^{2}$ & 0.49 & 0.59 & 0.61 \\
\hline$\alpha<0.32$ & Bias & 0.028 & -0.015 & 0.0060 \\
& RMSE & 0.051 & 0.043 & 0.027 \\
& $\mathrm{r}^{2}$ & 0.042 & 0.39 & 0.67 \\
\hline
\end{tabular}


Table 4. Effect of the bare soil parameterization on key variables (daily mean values). $m$ : mean value, $\Delta$ : relative difference with simulation VAL1.

\begin{tabular}{lllll}
\hline & Simulation & VAL1 & VAL1a & VAL1b \\
& Bare soil albedo & constant & $f(\mathrm{VWC})$ & Forced \\
\hline Albedo & $m(-)$ & 0.39 & 0.34 & 0.36 \\
& $\Delta(\%)$ & - & -14.5 & -8.6 \\
\hline Net radiation & $m\left(\mathrm{~W} / \mathrm{m}^{2}\right)$ & 73.5 & 83.4 & 78.8 \\
& $\Delta(\%)$ & - & +13.5 & +7.3 \\
\hline Surface temperature & $m(\mathrm{~K})$ & 275.5 & 275.8 & 275.7 \\
& $\Delta(\mathrm{K})$ & - & +0.37 & +0.19 \\
\hline Ground heat flux & $m\left(\mathrm{~W} / \mathrm{m}^{2}\right)$ & -0.42 & -0.37 & -0.44 \\
& $\Delta(\%)$ & - & +11.1 & -5.0 \\
\hline Sensible heat flux & $m\left(\mathrm{~W} / \mathrm{m}^{2}\right)$ & 48.7 & 55.5 & 52.0 \\
& $\Delta(\%)$ & - & +14.1 & +6.9 \\
\hline Total evaporation & $m\left(\mathrm{~W} / \mathrm{m}^{2}\right)$ & 25.0 & 28.1 & 27.0 \\
& $m(\mathrm{~mm} / \mathrm{d})$ & 0.88 & 0.99 & 0.95 \\
& $\Delta(\%)$ & - & +12.1 & +7.9 \\
\hline Bowen ratio & $m(-)$ & 1.95 & 1.97 & 1.93 \\
& $\Delta(\%)$ & - & +1.5 & -1.0 \\
\hline Water content $5-\mathrm{cm}$ & $m(\%)$ & 20.9 & 20.5 & 20.7 \\
& $\Delta(\%)$ & - & -1.9 & -1.0 \\
\hline Total Runoff & $m(-)$ & 2.78 & 2.67 & 2.70 \\
& $\Delta(\%)$ & - & -3.9 & -2.7 \\
\hline
\end{tabular}


Figure 1. (a) Localization of the Zongo glacier in Bolivia. Image Blue Marble Jan-2004 (Credit: NASA's Earth Observatory) (b) Aerial view of the study area and localization of the ORE-AWS on the lateral moraine (Credit: Google Earth). (c) Simplified map of the Zongo catchment after Ribstein et al. [1995], also showing the ORE2-AWS on the glacier. 
Figure 2. Albedo data collected in the ORE-AWS (1-hr mean values). Only values measured between $9 \mathrm{~h}$ and $16 \mathrm{~h} 30$ are taken into account in order to remove the solar zenithal effect in the observed time series [see Gascoin et al., 2009a]. The dashed blue lines indicate the extremes values chosen for the bare soil albedo parameterization (Sect. 3.4). 
Figure 3. Overview of the data and simulation characteristics. 
Figure 4. (a) Plot of the three tested topographic index distributions (each distribution is fitted to a gamma-law). TID1: Sleepers River catchment; TID2: Somme River catchment; TID3: Non-glacierized area of the Zongo catchment (b) Observed and simulated soil water content in the top 5 -cm for each TID $\left(\mathrm{m}^{3} / \mathrm{m}^{3}\right.$, 1-day mean values $)$. The shaded area indicates a data gap due to datalogger's battery failure. 
Figure 5. Observed and simulated soil water content $\left(\mathrm{m}^{3} / \mathrm{m}^{3}\right)$ in the top 5-cm (1-day mean values). Simulation CAL0 corresponds to the run before calibration and CAL1 after calibration of the $a_{\tau 2}$ parameter. The shaded area indicates the data gap. 
Figure 6. Analysis of simulated albedo values for runs VAL1, VAL1a and VAL1b.

Top plots: simulated versus observed albedo (1-day mean values, 414 values from 01-Sep-2004 to 31-Apr-2006). The dotted line marks $\alpha_{b}=0.32$. Bottom plots: distribution of the residuals (SIM-OBS). 
Figure 7. Simulated versus observed ground heat flux (Ghfx) and upward longwave radiation (LWout) in $\mathrm{W} / \mathrm{m}^{2}$ (1-day mean values). b: bias $\left(\mathrm{W} / \mathrm{m}^{2}\right)$, RMSE: root mean squared error $\left(\mathrm{W} / \mathrm{m}^{2}\right), \mathrm{r}^{2}$ : coefficient of determination. 
Figure 8. Effect of the bare soil albedo parameterization on the terms of the surface energy balance. Monthly mean values from 01 September 2004 to 31 March 2006 (labels: 1 for January). 
Figure 9. Effect of the bare soil albedo parameterization on the total runoff. Monthly mean values from 01 September 2004 to 31 March 2006. 
Zongo glacier $\rightarrow 0$ BOLIVIA
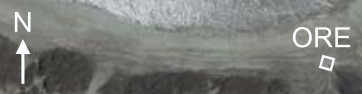

$0.500 \mathrm{~m}$

(c)

1

Huayna Potosi

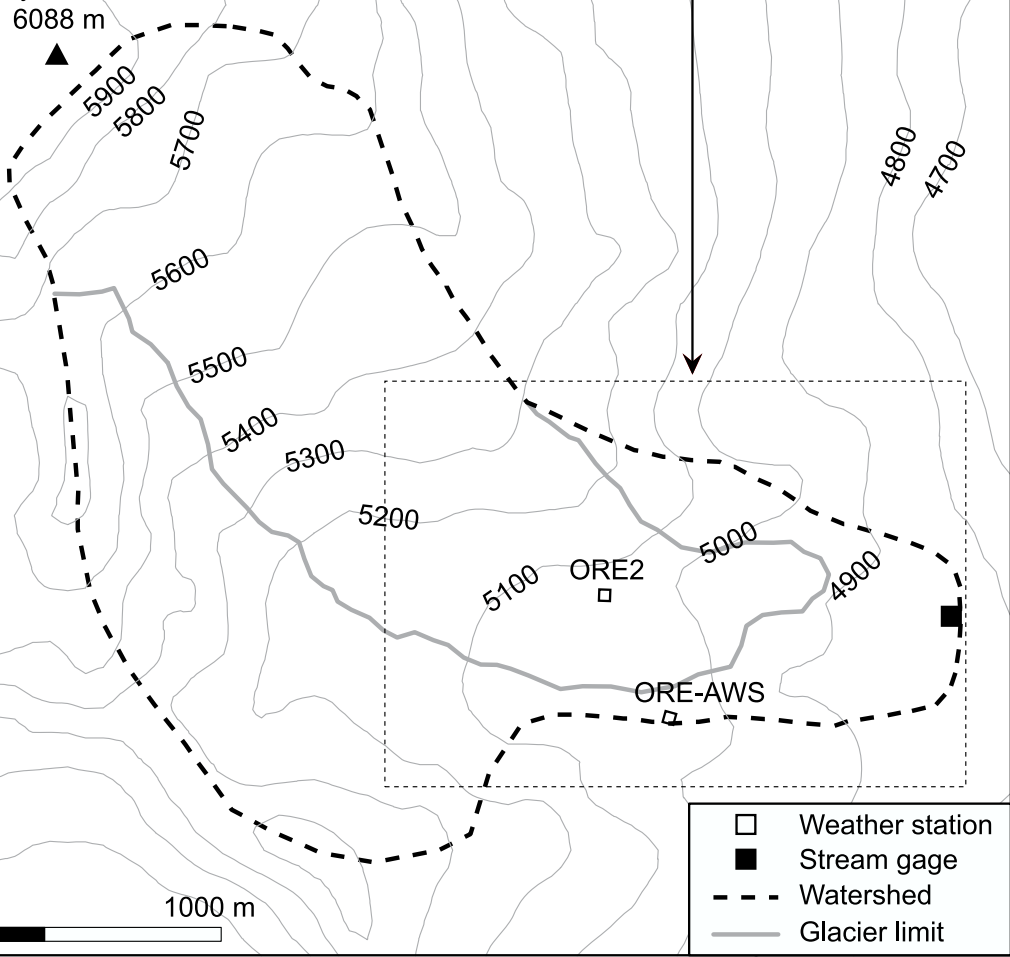


Albedo (1-hr mean values)

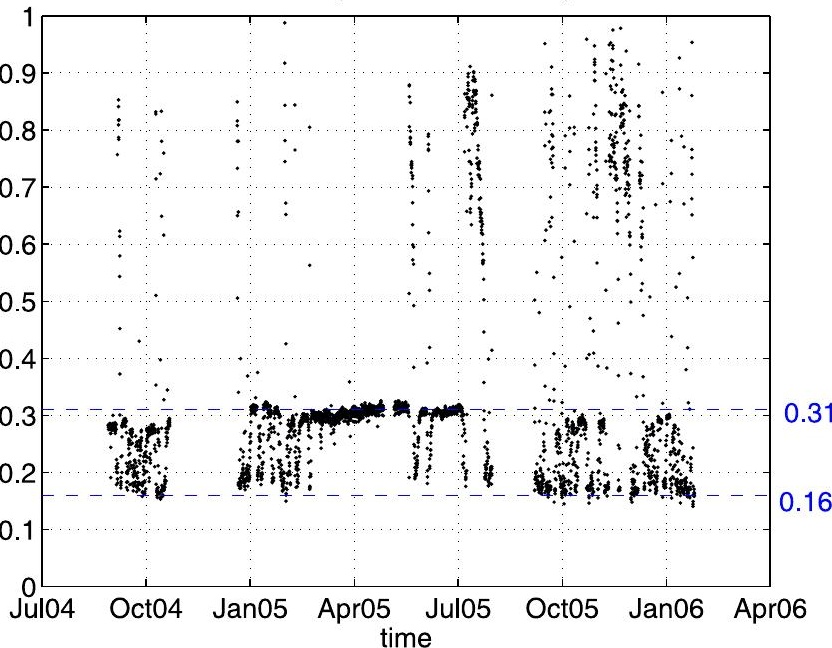


0405

0506

0708

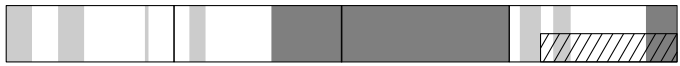

$$
1
$$

1-Sep-04

1-Sep-05

1-Sep-06

1-Sep-07

1-Sep-08

Legend

AWS dataset

VIIS VWC data

No data

Reconstructed data

Data 

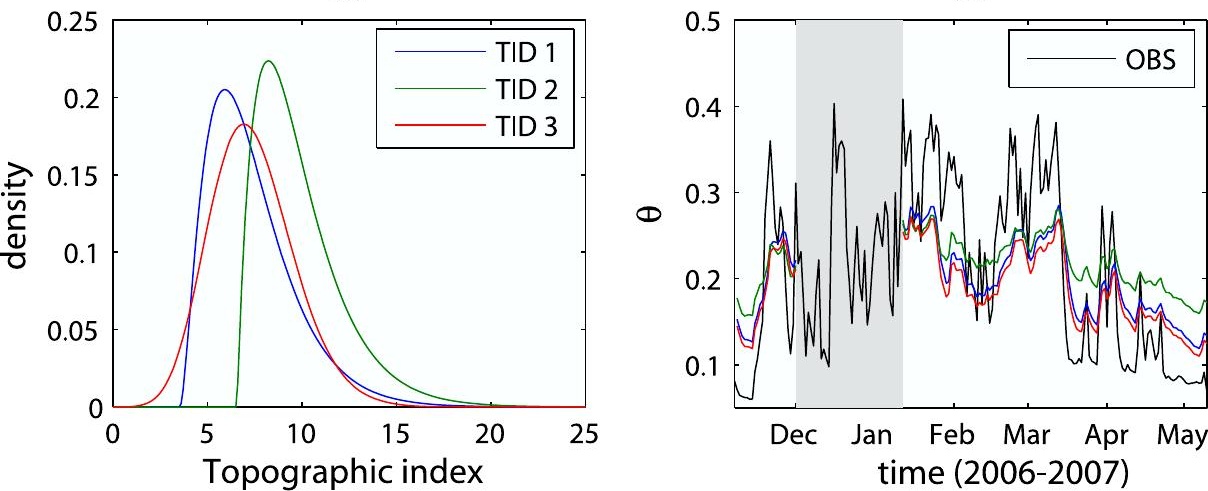


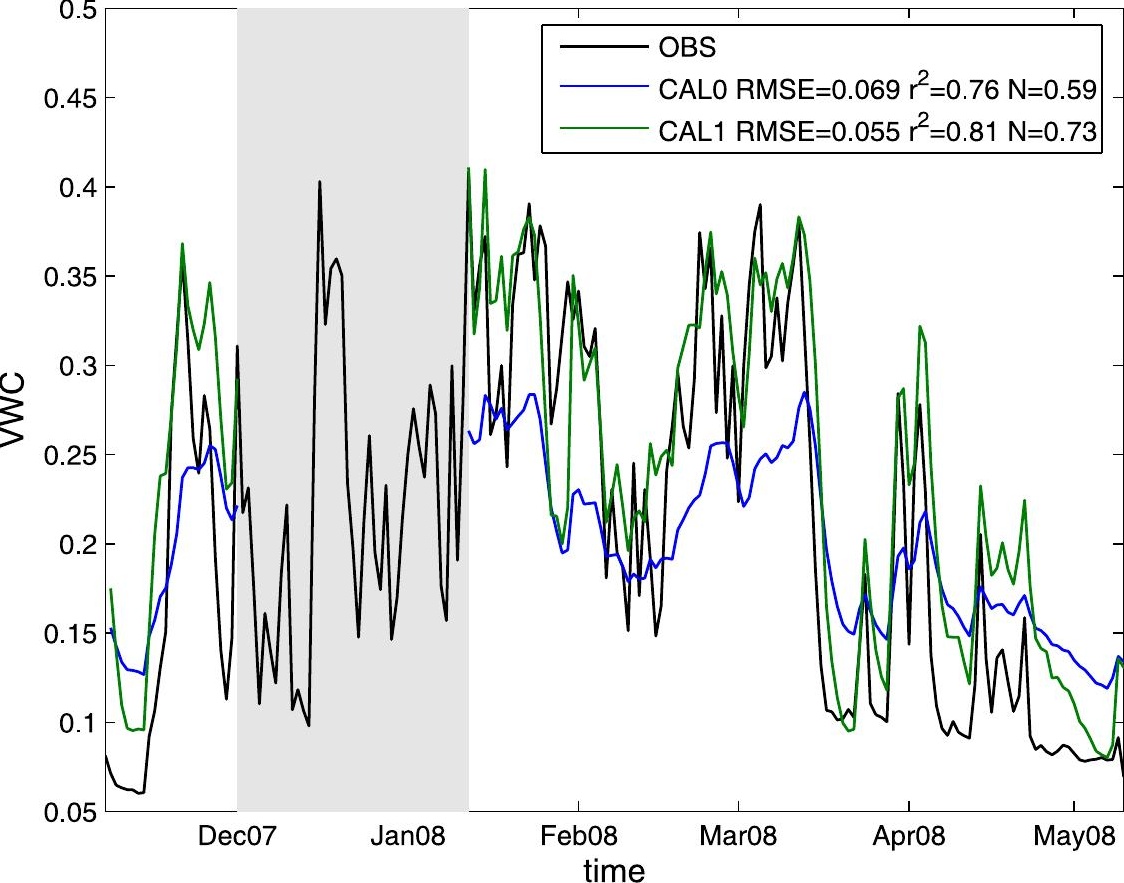



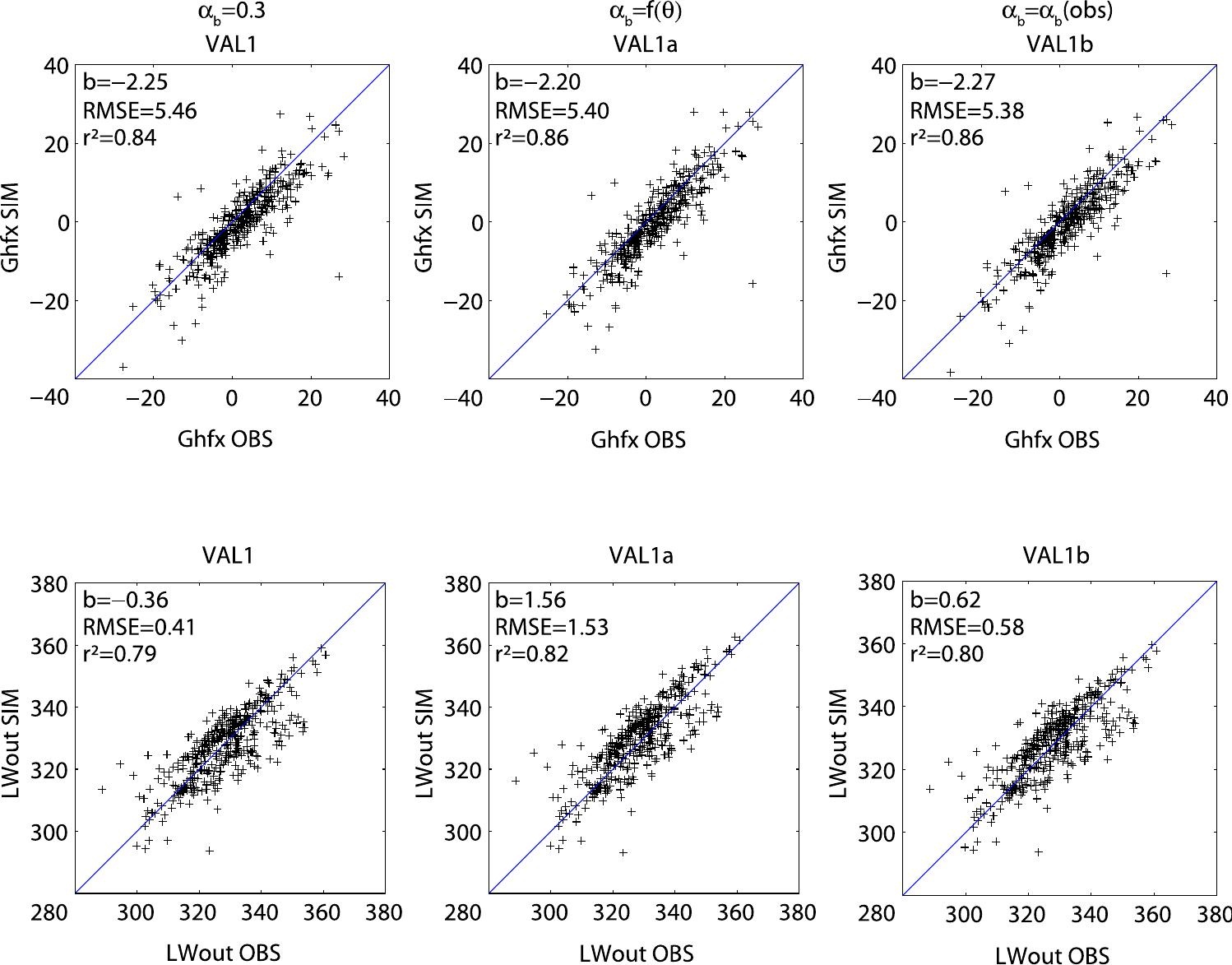
Net radiation $\left(\mathrm{W} / \mathrm{m}^{2}\right)$

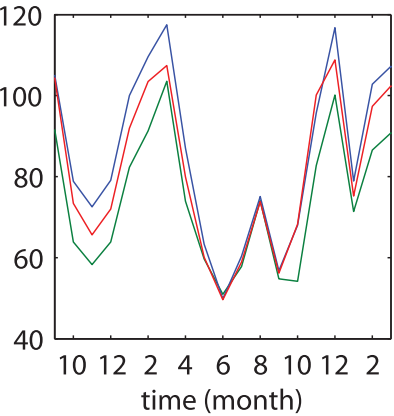

Ground heat flux $\left(\mathrm{W} / \mathrm{m}^{2}\right)$

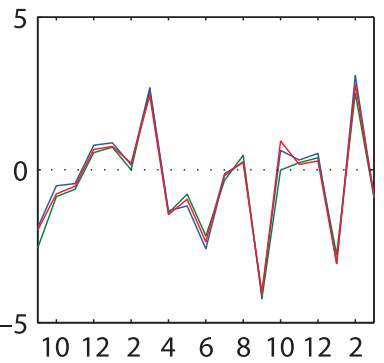

Total evaporation $(\mathrm{mm} / \mathrm{d})$

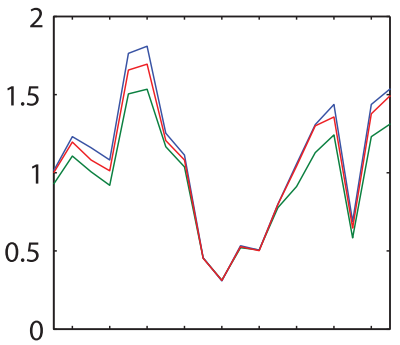

Sensible heat flux $\left(\mathrm{W} / \mathrm{m}^{2}\right)$

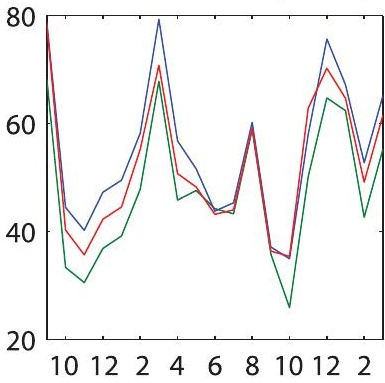

Surface temperature (K)

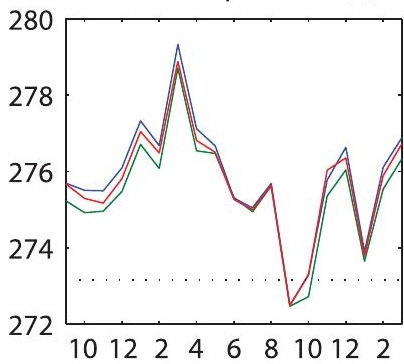

$1012 \quad 2 \quad 4 \quad 6 \quad 8 \quad 1012 \quad 2$

Legend

VAL1: $\alpha_{b}=0.3$

VAL1 $a: \alpha_{b}=f(\theta)$

VAL1b: $\alpha_{b}=\alpha_{b}$ (obs) 
(a) Total runoff $(\mathrm{mm} / \mathrm{d})$

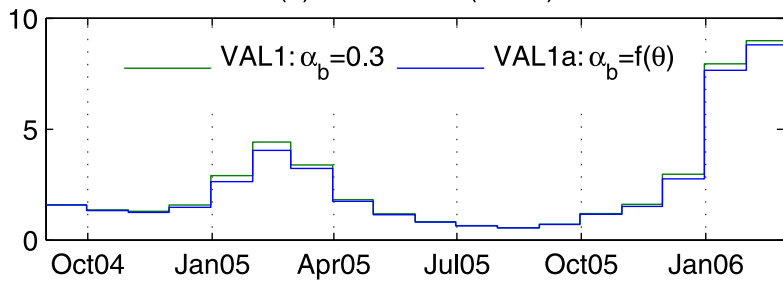

(b) Relative difference between VAL1 and VAL1a (\%)

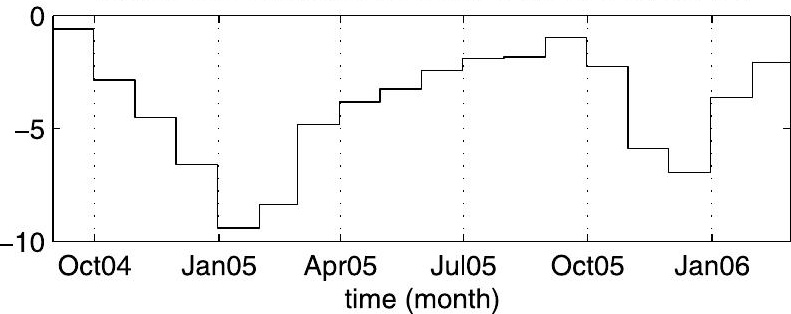

